\title{
Crime in the new U.S. epicenter of COVID-19
}

\author{
Steven James Lee ${ }^{1,2} \cdot$ Daniel Augusto $^{1}$
}

Accepted: 29 November 2021 / Published online: 4 January 2022

(c) The Author(s), under exclusive licence to Springer Nature Limited 2021

\begin{abstract}
In the latter half of 2020, Los Angeles was dubbed by the media and academicians as the latest epicenter of COVID-19 in the United States. Using time-series analysis on Los Angeles Police Department crime data from 2017 through 2020, this paper tests the economic theory of crime, routine activities theory, social isolation theory, and structural vulnerability theory to determine whether they accurately predicted specific crime rate movements in the wake of COVID-19 in the city of Los Angeles. Economic theory of crime was supported by the data, and social isolation theory and structural vulnerability theory were partially supported. Routine activities theory was not supported. Implications for policymakers and academics are also discussed.
\end{abstract}

Keywords COVID-19 $\cdot$ Crime rates $\cdot$ Fraud $\cdot$ Sex crimes $\cdot$ Violent crimes

\section{Introduction}

The SARS-CoV-2 (COVID-19) pandemic continues to surge across the globe. Within the U.S., certain regions fare better than others. Early on, New York City reported more cases than the entirety of China (Mahbubani and Mosher 2020), with estimates of 24,000 deaths above expectations during the peak of the outbreak (Hellmann 2020). By the end of 2020, the news media dubbed Los Angeles the new COVID-19 epicenter (Stringini and Hiramoto 2020; Haskell 2020), with LA County boasting the most U.S. cases $(635,000)$ and deaths $(9000)$ as of December 2020. One month later, LA continued to lead the U.S. with 1 million cases and 15,000 deaths (Chodosh 2021). By comparison, there were 19.7 million cases and 341,000 deaths across the U.S. (Reuters 2020). In the same period, global COVID cases topped 82 million, and worldwide deaths reached 1.8 million (Salyer et al. 2021). Despite the seemingly-endless struggles presented by the pandemic, stakeholders have focused more on COVID's impact on physical health (Dunton et al. 2020), mental health

Steven James Lee

s.lee8427@0365.ncu.edu

1 Northcentral University, La Jolla, CA, USA

2 California State Polytechnic University, Pomona, Pomona, CA, USA 
(Panchal et al. 2021), and household finances (Klein and Smith 2021) than crime rates during the outbreak.

Two thousand and twenty was an eventful year for Los Angeles. The metropolis confirmed its first case of COVID-19 on January 26, 2020 (Champlin 2020). On March 4, 2020, Los Angeles County declared an emergency after confirming six new cases within a 48-h period. On March 13, the Los Angeles Unified School District closed all schools within its jurisdiction for two weeks; Governor Newsom later extended school closures through the end of 2020. Mayor Eric Garcetti ordered all bars, nightclubs, entertainment venues, and gyms closed on March 15 through March 31, 2020. Four days later, Garcetti issued Los Angeles' first stay-at-home order. On April 7, Mayor Garcetti issued an emergency order requiring essential workers to wear face coverings and for employers to implement physical distancing measures (Altman et al. 2021). Los Angeles County extended its stay-at-home order until August on May 12. Governor Newsom required masks or face coverings to be worn in public and at work across the state on June 18. On July 1, Los Angeles County added beaches to its list of closures. On August 28, Newsom announced California's migration from a state watch list tracking COVID-19 cases to a fourtier color-coded system (purple as most severe and yellow as most mild), dictating which counties may permit businesses to reopen. Then, on November 19, Governor Newsom initiated a curfew from $10 \mathrm{pm}$ to 5 am for all California counties located in the purple tier, including Los Angeles (Bay Area News Group 2020). Three days later, Los Angeles County prohibited outdoor dining (Altman et al. 2021).

Scholars who have investigated the impact of COVID-19 on crime focused on a specific country such as Spain and Portugal (Redondo et al. 2020), Germany (Ritscher 2021), Australia (Payne et al. 2020), China, Hong Kong, and Taiwan (Xu et al. 2021), and the U.S. (Boman and Gallupe 2020). Other researchers narrowed in on specific crimes, including financial crimes (Mills 2020), drug trafficking and gang activities (Gomez 2020), and domestic violence (Hsu and Henke 2020).

Researchers have produced articles on a host of COVID-related topics, from social distancing (Frois 2020) to shelter-in-place orders (Friedson et al. 2021) to crime rates (Boman and Gallupe 2020). However, despite several research projects that study COVID-19, no study to date compares crime rates before and during the crisis within a geographic epicenter. The present study addresses this research gap by targeting crime in the city of LA. With more people remaining in their homes, a mixture of the population following restrictions and lockdown orders, and large swaths of Americans falling ill, entering hospitals, and dying, the question arises: which crimes have increased and decreased during the pandemic? Surely, such sweeping shifts in demographics suggest changes within the criminal mind as motivation, opportunity, and guardianship evolve.

\section{Literature review}

At the time of this writing, COVID-19 has begun its second year. This paper tests several popular criminological theories by analyzing LA crime rates over the past 5 years. We recount the discussion so far within the academic literature pertaining 
to COVID-19 and crime rates, highlighting the challenges to studying crime during the pandemic.

\section{COVID-19 crime research}

Several studies have analyzed crime during the first year of COVID-19. Similarities and differences exist between disparate offenses as well as countries and even cities where they occur. The U.S. is no different.

\section{Crime in various countries}

A common challenge in criminology is the lack of generalizability with many findings, particularly across different parts of the world. Payne et al. (2020) investigated the relationship between violent crime and social distancing regulations in Queensland, Australia. They found that most types of assault had greatly declined, but domestic violence remained unchanged, suggesting that domestic violence crimes, or at least their tracking and reporting, are resistant to social distancing measures and other virus transmission safeguards.

Cheung and Gunby (2021) found different results in New Zealand using monthly victimization reports from New Zealand Police from 2014 to 2020, combined with Google mobility data during the same period. They saw increases in mobility and decreases in property crime in residential areas. However, crimes against the person were uncorrelated with increased residential mobility.

Ashby (2020) studied crime data in major U.S. cities at the beginning of the pandemic. He found no significant changes to serious assault in public or residences, but some U.S. cities saw reductions in residential burglaries and motor vehicle theft. Redondo et al. (2020) surveyed experts and managers in Spain's correctional system and found significant decreases in thefts, hate crimes, property crimes, and police arrests, among others. Cyber-crimes associated with domestic violence, frauds by internet, online hate crimes, and failure to comply with ordinances and police orders (largely resulting from shelter-in-place laws) all increased.

The United Nations Office on Drugs and Crime (2020) also reported that robbery, theft, and burglary declined by approximately $50 \%$ in many of the countries studied, and the countries with the strictest lockdown measures saw even greater decreases in those crimes. Additionally, some countries experienced a $25 \%$ decline in homicides. However, the changes to crime rates were found to be short-lived, with prepandemic trends re-emerging.

\section{Specific crime rate changes}

Other criminologists have focused on specific crimes during the pandemic as opposed to specific countries. Layachi (2020) examined Interpol press releases related to the COVID-19 pandemic and found increased pharmaceutical crimes, including fraud and drug trafficking. Many of those offenses were committed by organized criminal groups. 
Dietze and Peacock (2020) offered a different outlook on drugs during the pandemic. While traditional supply chains have been disrupted, the internet and social media have connected dealers and users in new ways, such as dark web forums and blockchain and cryptocurrency markets. Decreased mobility outside of residential areas may decrease illicit drug use for fear of being caught, but increased stress and frustration may cause renewed use in the home.

Usher et al. (2020) stressed the impact of COVID-19 on family violence, specifically physical, sexual, and psychological abuse of women and children in the home. Social isolation means increased contact with abusers and less support-both extended familial and government-based-for victims. Shelter-in-place orders prohibit households from mixing, and many government offices are closed to the public as workers continue to provide services and complete administrative tasks remotely.

Across Asia and the West, Xu et al. (2021) discovered increased stigmatization, discrimination, and hate crimes against various Chinese and other Asian populations. Wuhan and Hubei (China) residents, overseas Chinese and other Asian subethnic groups, and those of African descent residing in mainland China all suffered increased persecution by individuals, businesses, and even municipalities. Fraud (Association of Certified Fraud Examiners 2020) and tax scams (United States Internal Revenue Service 2020) also rose throughout 2020 in the midst of COVID-19. Widespread calamity triggers government responses, which in turn pave the way for fraud within economic relief public programs, which extends to individuals, small businesses, and large corporations.

\section{Crime trends across the U.S. during the pandemic}

Shortly after the pandemic reached the U.S., scholars began analyzing changes in crime rates throughout the U.S. Miller and Blumstein (2020) focused on the first 100 days following the arrival of the virus and found that in $60 \%$ of U.S. cities, violent crime originally declined but then stabilized or increased back to pre-COVID levels. Robberies and aggravated assaults markedly declined, as did property crime and burglaries. However, cybercrime and parcel theft both increased. Violent crimes involving firearms substantially increased to their highest levels since 2016.

Boman and Gallupe (2020) found that minor crimes are often committed in peer groups while major crimes are often perpetrated by solo offenders. They found that, during 2019 and 2020, minor crimes decreased significantly while major crimes remained stagnant or increased. They opined that lockdown orders placed offenders within stressful situations, resulting in increased crime severity.

In comparing several cities within major metropolitan areas in March and April 2020, Wojcik and Austin (2020) found that overall crime in the United States decreased during the period while domestic violence notably increased. Restaurant burglary as well as wire, mail, healthcare, and government program fraud all increased. While the authors attribute much of these shifts to direct pandemic conditions (social isolation and distancing, shelter-in-place orders, etc.), they also pointed to indirect consequences as catalysts for crime surges throughout the country. Most notably, prisoner early releases on a large scale to reduce COVID-19 transmission 
within the correctional system possibly impacted national crime rate hikes, though indirectly.

\section{Theoretical frameworks}

This paper tests four salient theories in the criminal justice literature: the economic theory of crime, routine activities theory, social isolation theory, and structural vulnerability theory. Since the beginning of the COVID-19 pandemic, scholars have applied these theories to study crime rate changes in the U.S. and throughout the world. Each theory presents unique expectations of how crime changes in the midst of a global pandemic.

\section{Economic theory of crime}

Among the first to develop the economic theory of crime, Ehrlich (1973) conceived of crime the same way economists had framed financial decisions for many yearsas a utility function. When deciding whether to offend, criminals weighed the costs and benefits associated with committing the crime versus engaging in lawful enterprises instead. Offenders consider the potential increase in wealth or psychological well-being resulting from the crime against possible risks of financial diminution due to fines or time lost because of a prison sentence as well as the corresponding psychic disadvantages. Ehrlich (1973) proposed this theory in contrast to the twentieth-century mainstream view that crime was a deviant act committed by those who suffered from physical deformity, psychological torment, or aberrant socio-economic conditions.

Cheung and Gunby (2021) applied Ehrlich's (1973) theory to the present-pay pandemic period. Built into the decision-making process is the criminal's perceived risk and reward in committing an offense. Normally, a bustling mall yields not only rewards of stealing store merchandise but also personal property of patrons. In a lockdown with limited hours or closed businesses, the perceived reward decreases both in terms of aggregate amount and risk probability. While the reward decreases, the associated risk of being caught simultaneously increases. Within less-crowded areas, perpetrators stand out. Also, many closed stores maintain alarms and other security measures to deter theft and other crimes. Thus, under the economic theory of crime, most commercial crimes should decrease during a pandemic, and property-related crimes in residential areas should likewise decrease. However, crimes against the person as well as fraud offenses should increase in residential locations.

To test the economic theory of crime during the pandemic, Cheung and Gunby (2021) employed time series analysis on Police Victimization and Google mobility data for New Zealand. Property crimes in non-residential areas decreased during the pandemic by about 57\%. Property crimes in residential areas and crimes against the person in non-residential areas declined by $30 \%$. Crimes against the person in residential areas reduced $42 \%$. The mobility data showed decreased patronage in nonresidential areas along with a swelling of the New Zealand population in residential 
areas (Cheung and Gunby 2021). Crimes against the person within residential areas did not correlate with increased time spent at home.

\section{Routine activities theory}

Cohen and Felson (1979) presented routine activities theory in answer to the sociological paradox of the era: why did crime increase in the 1960s when the leading indicators of crime (high school graduation rate, employment rate, and median household income) simultaneously increased during the same period, especially for racial minorities? Routine activities theory closely resembles the economic theory of crime. Whereas economic theory posits offenses based on the criminal's perceived risk-reward tradeoff, routine activities theory conceptualizes crime as an occurrence at the intersection of motivated offenders, suitable victims, and lack of security or guardians to prevent the offense.

Routine activities theory postulates three components of crime: motivated offenders, suitable targets, and capable guardians (Cohen and Felson 1979; Payne et al. 2020). Generally, as offender motivation increases, crime increases. As the number of suitable targets increases, so does crime. However, as capable guardians or protections-be they security guards, firewalls, etc.-increase, crime decreases. Under routine activities theory, motivated offenders and suitable targets would both be expected to decrease in non-residential areas because there are fewer people frequenting those locales. Meanwhile, capable guardians in the way of mask mandates, social distancing, curfews, and the like should increase and thereby decrease crime in non-residential areas. Also, because most people are inhabiting residential areas most of the time, residential-based crimes should increase.

Payne et al. (2020) examined this convergence of crime during the routine activities of everyday life during the present pandemic. They predicted, similar to Cheung and Gunby (2021) that containment measures put in place by local, regional, and national governments would substantially shift these convergence patterns between offenders and victims. Using Google mobility data in Australia in combination with the country's crime data, Payne et al. (2020) surmised that serious assault (inflicting bodily harm, particularly against members of vulnerable or special populations such as elders or peace officers) and sexual offenses would both decrease during the pandemic - at least in the early lockdown period. By contrast, common assault (unwanted bodily contact not resulting in physical harm) and domestic violence would remain steady during mass containment.

Of the crimes considered, Payne et al. (2020) found decreases in serious assault rates in Queensland, Australia: 12.7 incidents per 100,000 people in April 2020, down from 18.3 per 100,000 the prior month-a $30 \%$ reduction. In fact, Payne et al. (2020) pointed out that the serious assault rate in Queensland had not fallen to the April 2020 level since July of 2015. Similarly, sexual offending also fell to 8.3 per 100,000 (down from 9.2 per 100,000 the month before-a 10\% reduction), which was the lowest sexual assault rate in Queensland since 2014. However, the Payne et al. (2020) study failed to produce significant results regarding crime rate changes of common assault and breaches of domestic violence orders. 


\section{Social isolation theory}

Shelter-in-place ordinances, commonplace during the coronavirus outbreak, force members of a household to remain in that space except to engage in essential activities like grocery shopping or fulfilling employment responsibilities outside the home (for essential workers). During the pandemic, people are removed from their normal social environments like work, school, clubs, and church. Usher et al. (2020) noted that this disruption to everyday life also strains relationship within the family unit, often resulting in stress and increased violence. Combined with a lack of government and community-based support, victims are at increased risk of domestic violence in the home.

The literature has linked social isolation to victimization in other crimes, most notably fraud. During normal (non-pandemic) times, elderly persons commonly suffer from isolation as a result of limited mobility due to health reasons as well as cumulative losses of spouses, older family members, and peers. Lichtenberg et al. (2013), Lichtenberg et al. (2016), and DeLiema et al. (2018) all investigated determinants of elder financial exploitation using the Health and Retirement Study data across multiple years. Depression and low social-needs fulfillment (i.e., social isolation) constituted significant causes of fraud victimization.

Usher et al. (2020) collected several news sources that cited increases in social isolation and, therefore, domestic violence during the pandemic. In France, domestic abuse complaints increased by $32 \%$ generally and 36\% in Paris during the first two weeks of mandatory stay-at-home orders in 2020 (Godin 2020). Similarly, the United States also saw dramatic surges of domestic violence ranging from 21 and 35\% (Wagers 2020).

\section{Structural vulnerability theory}

Tyler et al. (2015) recounted that the 1980s saw widespread implementation of community (proactive) policing in America. In an effort to strengthen ties between police departments and the rest of the community, police officers sought to control crime through increased stop, question, and frisk activities. These nonvoluntary contacts with the public, accompanied by zero-tolerance policies for various behaviors, led to increased arrests, court hearings, and incarcerations.

Samra et al. (2020) recalled six social forces driving structural vulnerability to violence against racial minorities in America: deindustrialization (chronic unemployment), rising wealth disparity amidst racial and ethnic segregation, disinvestment in public-private sector services, rise in drug abuse and underground economies, routinization of police brutality and punitive sentencing, and gentrification. Samra et al. (2020) predicted that violence against racial minorities would increase as a result of COVID-19 due to the intersection of racism, poverty, and violence, all of which lie at the heart of seismic events like the present pandemic and have been shown to disproportionately affect racial minorities. 
Samra et al. (2020) noted that, before the pandemic, African American men were 14 times more likely to be victims of firearm-related deaths than Caucasian men. McKay et al. (2020) found the total number of daily firearm-related injuries and deaths in the United States increased by $30 \%$ following statewide emergency declarations and $18 \%$ after stay-at-home orders were announced. Everytown for Gun Safety Support Fund (2021) released a report that detailed African Americans of both genders were 10 times as likely as Caucasians to die by firearms during 2020. Under structural vulnerability theory, one would expect violent crimes against racial minorities to increase during the pandemic due to various factors like poverty resulting from loss of work and increased segregation via shelter-inplace orders during the pandemic.

\section{Method}

This paper tests the theories by measuring crime rate changes before and during the COVID-19 pandemic in LA. Existing studies have either looked at crime changes in other countries, those throughout the U.S. as a whole, or within LA specifically, but only during the early part of the outbreak. This work builds on other studies by determining whether the changes in crime highlighted by previous scholars apply to LA, the new U.S. epicenter of the pandemic.

\section{Data}

We used two open-source Los Angeles Police Department (LAPD) data files: crime data from 2010 to 2019 (LAPD 2021a) and from 2020 to the present (March 10, 2021; LAPD 2021b). Of the 28 variables included in the data set, the official file number, the date the crime occurred, the crime committed, the modus operandi of the criminal, the victim's age, sex, and descent (ethnicity), and the premises in which the crime occurred will constitute the variables of interest for this study. Analysis covered the period from January of 2017 through December of 2020 - a total of 48 data points (12 months per year for 4 years). This yielded a total number of offenses committed within LA $(n=872,137)$. Note that the figures below show crime rate changes over a 5-year period. The fifth year is forecasted based on the actual data points between 2017 and 2020 (4 years).

Criminology studies employing time series have varied in the number of data points used. Mohler et al. (2020) analyzed daily counts of calls for service in LA from January 2 to April 18 (108 data points). Payne et al. (2020) focused on COVID-19's influence on monthly crime rates in Queensland, Australia, between 2014 and 2020 (72 data points). Halford et al. (2020) studied daily crime rates reported to a single UK-based police force before and after COVID-19 from the same five-week period across 5 years ( 75 points). 


\section{Hypotheses}

The below hypotheses were tested:

$\mathrm{H}_{0}$ : There are no statistically significant differences between crime rates pre-pandemic and the present;

$\mathrm{H}_{1} \mathrm{~A}$ : Property crimes will decrease in commercial areas;

$\mathrm{H}_{1} \mathrm{~B}$ : Crimes against the person will decrease in commercial areas;

$\mathrm{H}_{1} \mathrm{C}$ : Crimes against the person will increase in residential areas;

$\mathrm{H}_{1} \mathrm{D}$ : Fraud-related crimes will increase in residential areas;

$\mathrm{H}_{2}$ : Crimes against the person will decrease;

$\mathrm{H}_{3}$ : Domestic violence in the home will increase; and

$\mathrm{H}_{4}$ : Violent crimes against racial minorities will increase.

\section{Methodology}

The LAPD-recorded offenses within the time period were categorized into four broad groups: crimes against the person, property crimes, fraud-related crimes, and others. Crimes against the person were further divided into sexual, violent, and other subcategories. Table 1 contains the filter criteria used to operationalize crimes constituting "property," "person, violent" "fraud," and "person, sexual."

Next, the data were filtered by hypothesis and summed by month within the 5 -year period. Table 2 depicts the filter criteria for each hypothesis.

SAS enterprise guide was then used to filter the data eight times-once for each hypothesis. The number of crimes corresponding to each hypothesis is listed in Table 3. Each filtered subset of data then underwent further analysis to detect trends before and during the COVID-19 outbreak in LA.

Time series analysis, which describes a series of observations over time, is made up of four components: trend, cycle, seasonal, and random (Whiteley 1980). For each data subset, 12-month moving averages were tabulated to account for the trend component. Because the number of months in a year is even, centered moving averages were also calculated. Crime rates corresponding to each hypothesis were plotted on a basic line chart overlaid with the center moving average line to smooth the data. In order to identify the trend of each data subset, the seasonal and irregular (cyclical) components of the data had to be removed, which formed the deseasonalized component within the data. To control for random variation of changes in crime rates, the deseasonalized component was then regressed onto the time component. The time series linear regression model was expressed thusly:

$$
Y_{t}=s(t)+\varepsilon_{t}
$$

where $Y_{t}$ is crimes, in thousands, at time $t, s(t)$ is the monthly effect, which was deseasonalized by dividing crimes by the seasonal component, and $\varepsilon_{t}$ comprises the random errors, also at time $t$. The regression is simple because the other variables have already been incorporated into the monthly crime effect, $s(t)$, via the filtration 
Table 1 Crime type keywords, LAPD crime data, 2017-2020

\begin{tabular}{|c|c|}
\hline Crime type & Key words \\
\hline Property & $\begin{array}{l}\text { - Arson } \\
\text { - Robbery } \\
\text { - Stolen } \\
\text { - Burglary } \\
\text { - Shoplifting } \\
\text { - Theft } \\
\text { - Trespassing } \\
\text { - Vandalism }\end{array}$ \\
\hline Person, Violent & $\begin{array}{l}\text { - Assault } \\
\text { - Battery } \\
\text { - Abuse } \\
\text { - Threats } \\
\text { - Homicide } \\
\text { - Rape } \\
\text { - Penetration } \\
\text { - Endangerment }\end{array}$ \\
\hline Fraud & $\begin{array}{l}\text { - Bunco } \\
\text { - Embezzlement } \\
\text { - Extortion } \\
\text { - Defrauding } \\
\text { - Dishonest } \\
\text { - Forgery }\end{array}$ \\
\hline Person, Sexual & $\begin{array}{l}\text { - Intimate } \\
\text { - Abuse } \\
\text { - Sex } \\
\text { - Sexual } \\
\text { - Lewd } \\
\text { - Copulation } \\
\text { - Rape } \\
\text { - Penetration } \\
\text { - Human (trafficking) }\end{array}$ \\
\hline
\end{tabular}

Table 2 Filter criteria by hypothesis, LAPD crime data, 2017-2020

\begin{tabular}{llllll}
\hline Theory & Hypothesis & Crime type & Location & Victim & Effect \\
\hline Economic & 1A & Property & Commercial & - & Decrease \\
& 1B & Person & Commercial & - & Decrease \\
& 1C & Person & Residential & - & Increase \\
& 1D & Fraud & Residential & - & Increase \\
Routine activities & 2 & Person (sexual) & - & $60+$ & Decrease \\
Social isolation & 3 & Person (violent) & Residential & - & Increase \\
Structural Vulnerability & 4 & Person (violent) & - & Minority & Increase \\
\hline
\end{tabular}


Table 3 Total crimes by filtered subset, LAPD crime data, 2017-2020

\begin{tabular}{lllc}
\hline Theory & Hypothesis & Filters & Number of crimes \\
\hline Economic & 1A & Property, commercial & 442,008 \\
& 1B & Person, commercial & 134,940 \\
& 1C & Person, residential & 101,963 \\
& 1D & Fraud, residential & 11,327 \\
Routine activities & 2 & Person (sexual), 60+ & 3168 \\
Social isolation & 3 & Person (violent), residential & 95,117 \\
Structural Vulnerability & 4 & Person (Violent), minority & 182,207 \\
\hline
\end{tabular}

process. Lastly, the time series was forecast 12 months into the future (through 2021).

\section{Results}

Figures 1 through 7 showcases the plots (crimes, in thousands), baseline (center moving average), and forecast for each data subset. Figure 1 contains the time series visualization for $\mathrm{H}_{1} \mathrm{~A}$. There is a downward sloping trend in overall property crimes within commercial areas in LA, and that trend sharpens during the fourth year (2020), particularly in the latter half when LA became the new U.S. hotspot for COVID-19. Notice that the forecast into the fifth year (2021) suggests these types of crimes will slightly rebound. This negative trend is highly significant $(p<0.001)$. Table 4 depicts the linear regression results for each hypothesis.

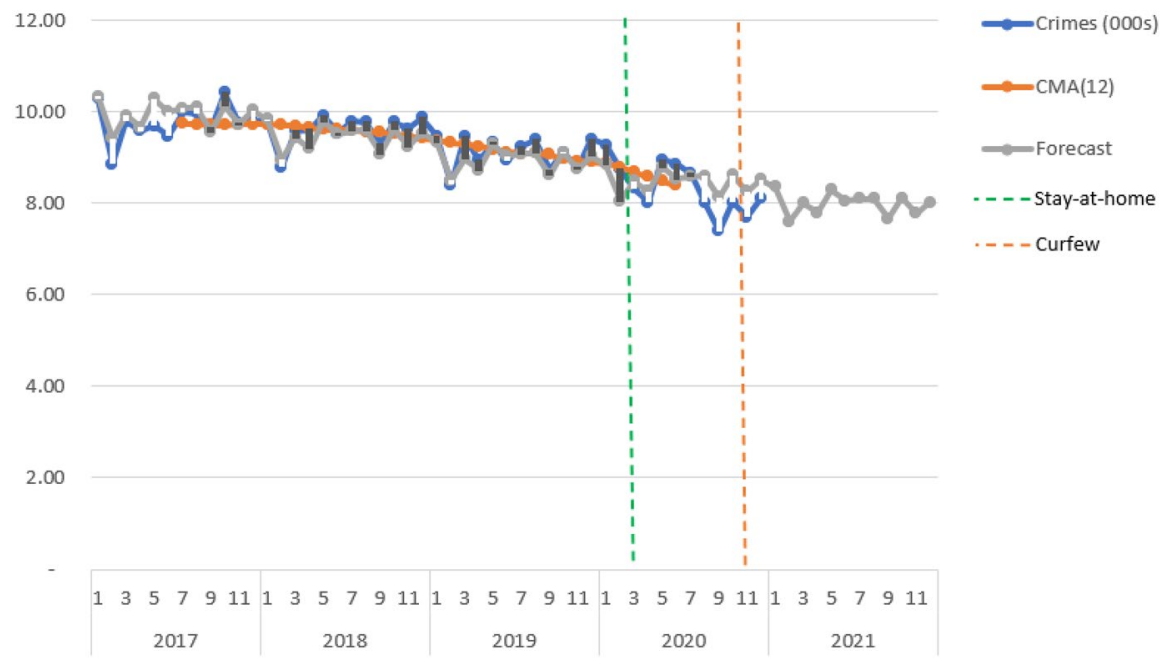

Fig. 1 Property crimes (commercial) LAPD crime data (2017-2020) 
Table 4 Time series linear regression results, LAPD crime data, 2017-2020

\begin{tabular}{lll}
\hline Hypothesis & Coefficient & Standard errors \\
\hline 1A & $-0.04 * * *$ & 0.003 \\
1B & $-0.02 * * *$ & 0.001 \\
1C & $-0.007 * * *$ & 0.0008 \\
1D & $-0.002^{* * *}$ & 0.0005 \\
2 & -0.0001 & 0.0001 \\
3 & $-0.006 * * *$ & 0.0007 \\
4 & $-0.01 * * *$ & 0.002 \\
\hline
\end{tabular}

$* * * p<0.01$

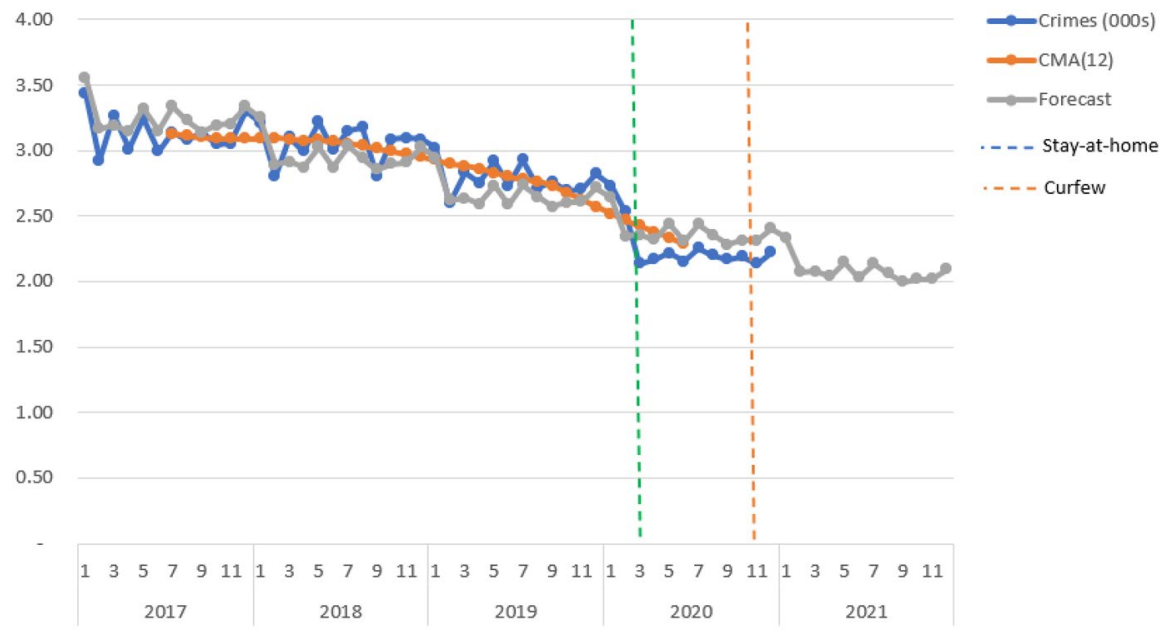

Fig. 2 Person crimes (commercial) LAPD crime data (2017-2020)

Figure 2 similarly shows a decline in crimes against the person in commercial areas over the 4 years and even into the fifth year, although the sharpest decline was, once again, in the fourth year (2020). The negative trend is also highly significant $(p<0.001)$ as shown in Table 4. Figure 3 depicts an overall downward trend in personal crimes in residential areas over the 4 years, except in the fourth year when Los Angeles became the latest COVID-19 hotspot. There was an uptick in crimes during the latter half of 2020, although the analysis forecast that these crimes would decline overall (despite seasonal variation) in 2021. Like the prior two, this statistic was highly significant $(p<0.001)$.

Unlike the other three predictions within the economic theory of crime, fraud crimes occurring in residential areas substantially decreased in 2020, as shown in Fig. 4. The analysis forecasts that the trend will continue to decrease-through to a more modest extent compared to the actual decrease that occurred in the fourth 


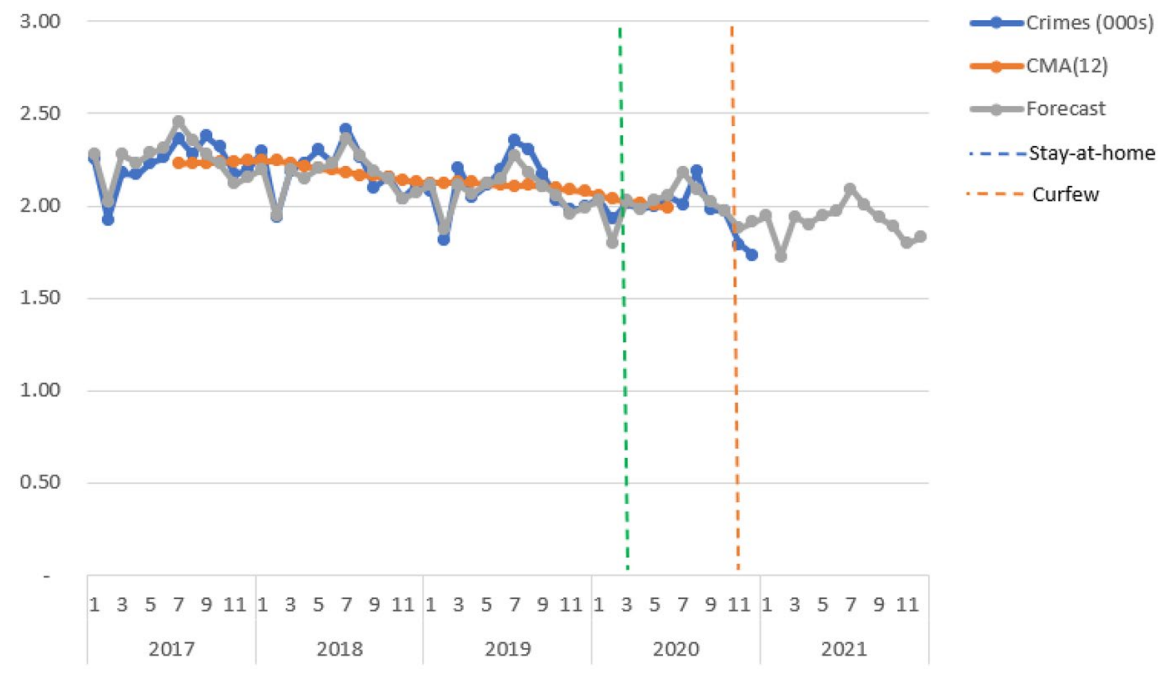

Fig. 3 Person crimes (residential) LAPD crime data (2017-2020)

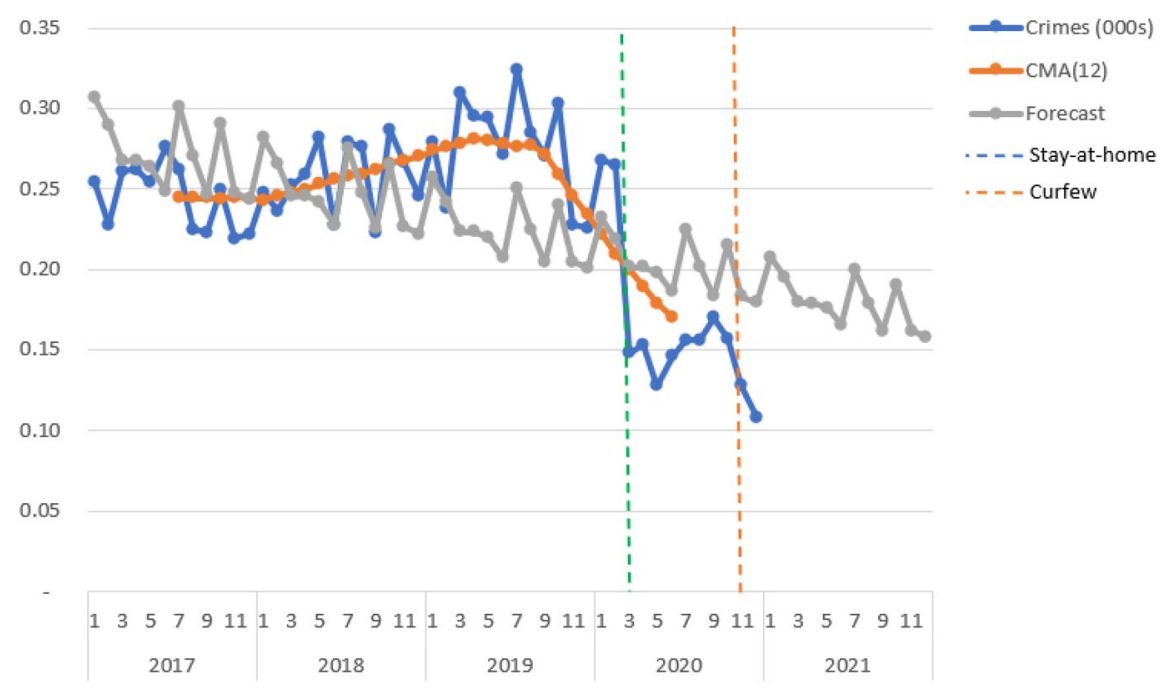

Fig. 4 Fraud crimes (residential) LAPD crime data (2017-2020)

year. This trend was highly significant $(p<0.001)$ just like the other three test statistics before it.

Figure 5 shows the seasonal trend of sexual crimes against elders (those aged 60 and older). As predicted by routine activities theory, however, there was a sharp decline in these crimes throughout the beginning and end of the fourth year. However, there was a substantial uptick (though modest compared to prior years) during the middle of 2020. The model forecasts a general increase in these crimes during 


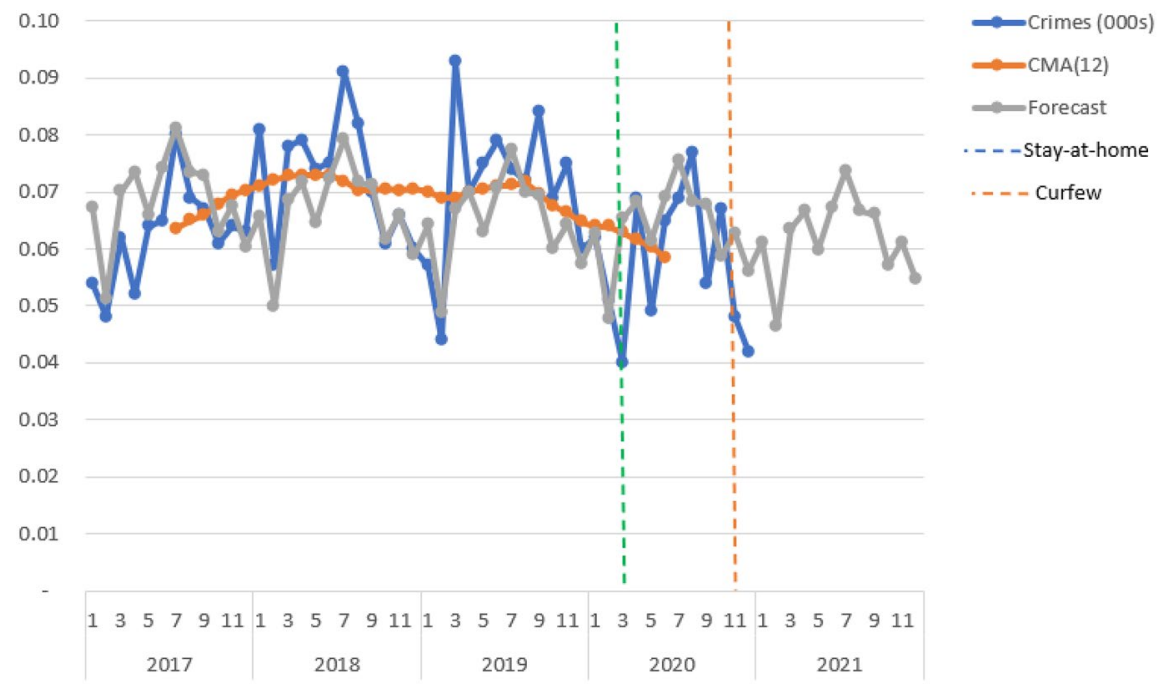

Fig. 5 Sexual crimes against 60+ LAPD crime data (2017-2020)

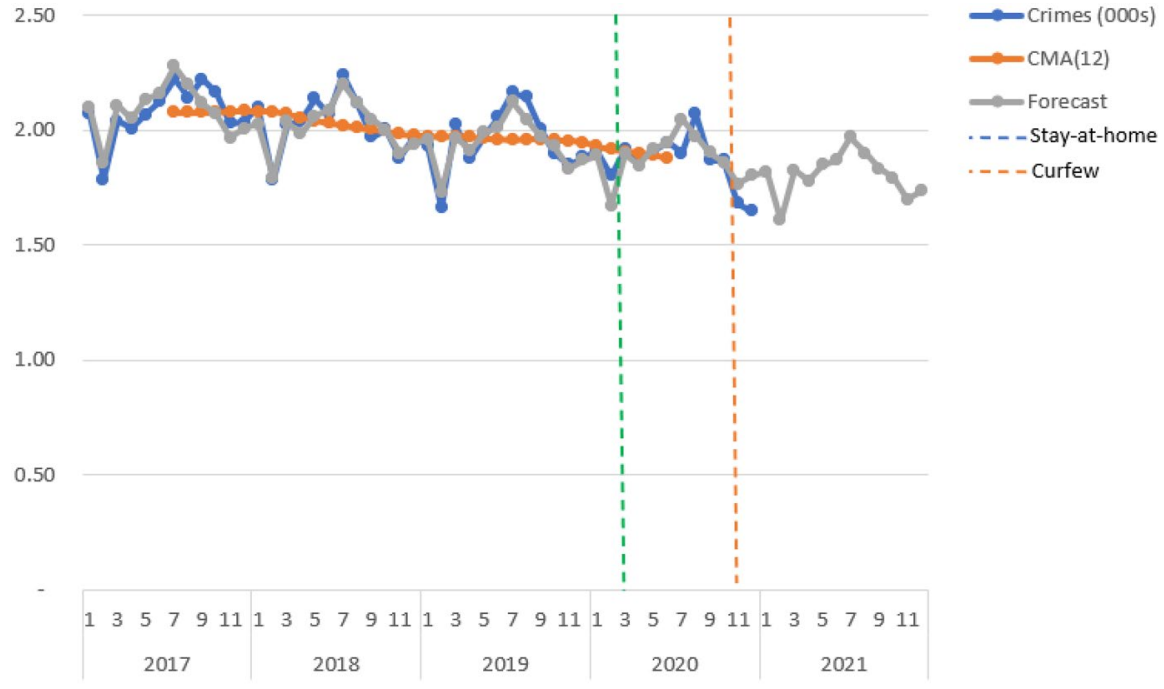

Fig. 6 Violent crimes (residential) LAPD crime data (2017-2020)

2021. It is important to note, however, that the test statistic for the fraud crimes in residential areas was not significant - the first one so far within the present analysis. The statistic was not statistically significant.

Figure 6 shows a slightly downward trend in violent crimes occurring in residential areas. However, the seasonal effect of increased crimes occurring during the summer persisted in 2020. Overall, markedly during the latter months of the fourth 


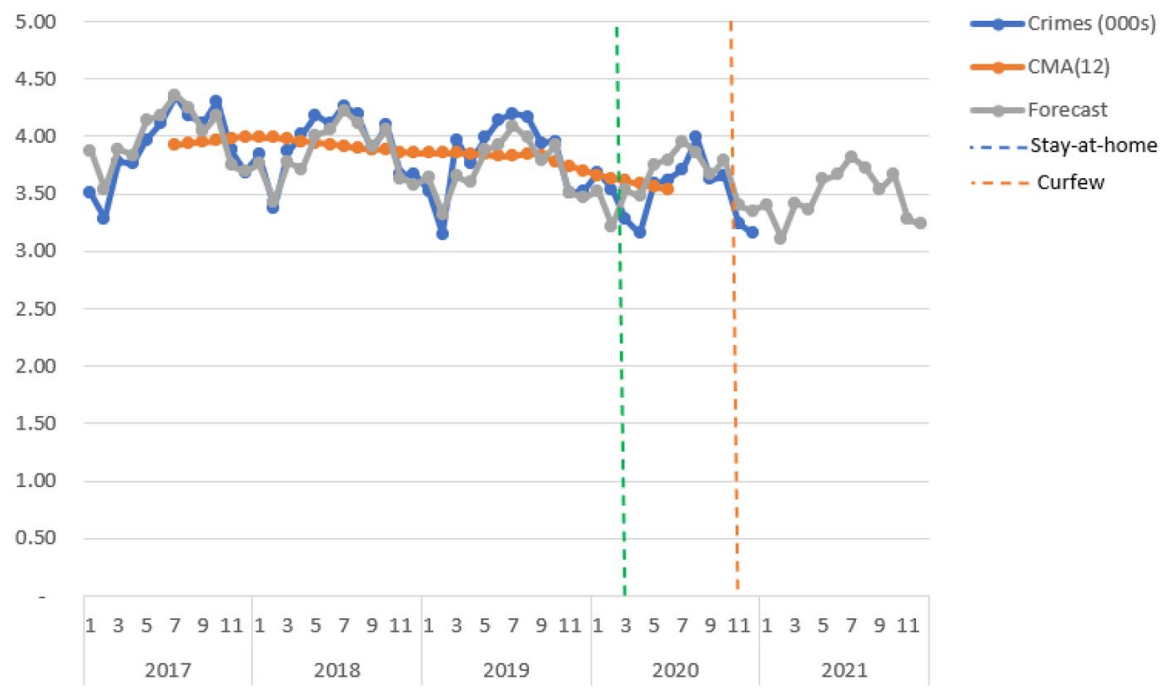

Fig. 7 Violent crimes against minorities LAPD crime data (2017-2020)

Table 5 Hypothesis results, LAPD crime data, 2017-2020

\begin{tabular}{ll}
\hline Hypothesis & Result \\
\hline 1A & Fully supported \\
1B & Fully supported \\
1C & Fully supported \\
1D & Not supported (direction) \\
2 & Not supported (significance) \\
3 & Partially supported \\
4 & Partially supported \\
\hline
\end{tabular}

year, these crimes continued to decrease. Specifically, violent crimes increased following stay-at-home orders but decreased once curfews were established. Overall, the model forecasts a general increase in these crimes, particularly during the fifthyear forecast. The statistic was highly significant $(p<0.001)$.

Lastly, violent crimes against minorities seemed to be the most seasonal of all, as depicted in Fig. 7. This trend continued throughout 2020 with only slightly sharper variation in oscillation compared to preceding years. The test statistic was highly significant $(p<0.001)$, and the model forecasts more modest seasonality in the data heading into the fifth year. These crimes also declined after stay-at-home orders and curfews. Nevertheless, there was a notable increase in crime mid-year.

Table 5 shows a summary of the results in terms of hypothesis support. Three of the four hypotheses contained within the economic theory of crime- $\mathrm{H}_{1} \mathrm{~A}, \mathrm{H}_{1} \mathrm{~B}$, and $\mathrm{H}_{1} \mathrm{C}$ - were fully supported by the data. $\mathrm{H}_{1} \mathrm{D}$ predicted residential fraud crimes would increase when in fact they drastically decreased. $\mathrm{H}_{2}$ was not supported as the 
statistic was not statistically significant. Finally, $\mathrm{H}_{3}$ and $\mathrm{H}_{4}$ were partially supported due to variation within the fourth year.

\section{Discussion}

This study tested whether four crime theories accurately predict crime rates in the city of L.A. as the new U.S. epicenter of the pandemic in the latter half of 2020. The economic theory of crime accurately predicted crime rates throughout the pandemic. Routine activities theory's prediction regarding sexual crimes against the elderly lacked statistical significance. Social isolation and structural vulnerability theories, although partially supported, failed to break the seasonal trend of residential violent crimes and those against minorities peaking during the second and third quarters, and troughing during the fourth and first quarters, which mirrored the preceding years. Though statistically significant, it could be argued that continuing the trend of crime rate changes from prior years, combined with the intra-year oscillations during 2020, lessens the effectiveness of social isolation and structural vulnerability theories to predict changes during the pandemic.

Crimes predicted by the economic theory of crime showed substantial movement in accordance with findings from prior studies following the stay-at-home orders in March 2020 and again after curfews were implemented in November that same year. Regarding the economic theory of crime, prior literature found drastic reductions in those crimes between 30 and 57\% (Cheung and Gunby 2021). In this study, crime rate decreases following stay-at-home orders varied drastically from less than $1 \%$ (residential crimes against the person) to $48 \%$ (commercial person crimes). Following curfews, changes ranged from less than $1 \%$ increase (commercial property) to a $110 \%$ decrease (fraud crimes, year-over-year). Also, economic theory of crime was the only theory whose predictions strengthened along with the COVID-19 intensity in L.A.

Routine activities theory has also varied in COVID-19 crime rate change predictions in the literature - to the magnitudes of 10\%-30\% decreases (Payne et al. 2020). In this study, sexual crimes against elderly victims actually saw a $13 \%$ increase following stay-at-home orders compared to the prior month and a modest $1 \%$ decrease year-over-year. Following curfew, these crimes decreased by a staggering $64 \%$ compared to the end of 2019, as well as a $43 \%$ reduction year-over-year. Unlike the economic theory of crime, changes in routine activities theory-based crimes split in terms of direction between the aftermath of stay-at-home orders and that of curfews; Overall, sexual crimes against victims aged 60+ dramatically decreased in Los Angeles.

Like the other theories, social isolation predictions have varied greatly in the literature: from 21 to $36 \%$ increase (Godin 2020; Wagers 2020). The present study discovered less than $1 \%$ decreases following stay-at-home orders (both from the end of 2019 and year-over-year). Following end-of-year curfews, these crimes had dropped by $14 \%$ (end of 2019 and year-over-year). Yet, violent residential crimes spiked during the middle of the year. 
Finally, structural vulnerability, while lacking specific crime rate predictions within the literature, was found to account for an $18 \%$ to $30 \%$ increase in incidents of violence reported by minority victims (McKay et al. 2020). During the months immediately following stay-at-home orders and curfews, there were drops to the degree of $12 \%$ (compared to prior month) and 19\% (year-over-year) as well as less than $1 \%$ (compared to 2019) and 12\% (year-over-year), respectively. Like those crimes predicted by social isolation theory, changes in violent crimes against minorities did see spikes mid-year in 2020 but to a lesser magnitude and for a shorter duration.

A multitude of reasons may explain why some types of crimes failed to (or only moderately) conform to their respective theories. It is widely known that fraud is generally difficult to study as it has inherent confounding factors. Also, many people fail to realize they have been defrauded and therefore never report the crime. Additionally, many high-dollar, complex fraud cases require extended investigation time, which can delay reporting of arrests and convictions for sometimes years. In the present analysis, "cyberspace" was a crime location in the data, and it was included in the "residential" category. One could justifiably argue, however, that cyberspace should not be included. A similar argument could be made for crimes perpetrated against socially isolated victims.

Regarding residential violent crimes and violent crimes against minorities, fear of one's significant other and a lack of trust in the police by racial minority groups may partially explain the shrinking - though still noticeable-seasonality around these crimes in LA. It has been well documented that minority communities in the U.S., at least in part, do not trust (and are therefore less likely to report) crimes to police (Zaykowski et al. 2019). Additionally, minorities who have come to the U.S. illegally may hesitate to report crimes to the police for fear of deportation (Macias Jr 2019). It has also been demonstrably shown that victims of violent crimes are less likely to cooperate with law enforcement if they know their offenders in any way (Felson and Lantz 2016).

Past COVID-19 crime research posited that crime would generally decrease in commercial areas, but certain crimes-namely, violent crimes against womenwould increase. The present study's findings only partially support this prediction. As people largely obeyed stay-at-home orders, were socially distanced, and remained vigilant of inter-personal contact, the opportunity (perceived or real) to commit crimes in public places declined. Likewise, fraud and domestic violence victims were more commonly positioned to be affected by these crimes: People probably spent more time on their home computers, and domestic violence victims remained close to their abusers throughout the day. The explanation above also matches reports by some police officers describing crime during the COVID19 pandemic (Augusto et al. 2020). Only residential fraud crimes strictly violated their corresponding theory's prediction.

Rebounding effects observed in some of the results during 2020 might be explained by California's color-coded system whereby movement between tiers permits certain businesses to remain open or forces their closure, and businesses are expected to comply with the county's new tier ramifications immediately 
(Irick 2021). Therefore, general consumer confusion surrounding the state's multi-tiered system may explain variation in crime rates throughout COVID-19.

\section{Limitations}

One limitation is this study's scope comprising a single city. Though the premise of the paper was to determine whether traditional crime theories accurately predicted crime rates in the COVID-19 U.S. epicenter, the results may not generalize to other cities or countries. Another limitation is found in the data themselves. Sorting both crime types and locations into categories remains difficult and somewhat subjective, and assumptions must be made in terms of which crimes and locations should fall under which labels.

\section{Implications}

Policymakers might benefit most from two primary aspects of these results. First, efforts should be redoubled to spread awareness of crimes involving fraud against elders and violence against minorities. These are two of the most vulnerable populations who face inherent challenges in reporting crimes and obtaining justice. Second, data collection should be improved. This could take the form of a deeper understanding of crime types and locations as well as better-reasoned categorization techniques, with an eye toward future utilization for data-driven decisions and research. Reinforcing the importance of primary data collection, of which community members play a central role, as well as linking study findings with real-world application through community outreach efforts and other infrastructural changes should serve as top priorities for policymakers.

Crime prevention personnel might benefit from these findings by redirecting some resources away from crime prevention in public areas during lockdowns. Similarly, efforts toward community safety in residential areas might be enhanced. Public awareness campaigns related to residential-type crimes might be useful as well.

\section{Future research}

Further research might also explore future crime rates as the pandemic continues to unfold. Additionally, pandemic crime rates in other major cities should be explored to determine if crime rates have relationships with certain types of response efforts and public health policies. Perhaps most importantly, future studies should address variation in magnitude regarding crime rate changes between different offenses. Additional qualitative research might also provide some context to support the existing quantitative studies on crime during COVID-19. Finally, other data sets should be consulted regarding perpetrator information related to the crimes espoused in the prevalent crime theories discussed in this paper. 


\section{Conclusion}

This paper tested whether four prevalent theories of crime, which accurately predicted crime rate changes during COVID-19, would continue their forecasts in a pandemic epicenter. Overall, this research found that most of the theories significantly predicted crime rate changes during the COVID-19 pandemic at the pandemic's new epicenter. Routine activities theory did not. Areas that fail to handle the pandemic well may experience greater oscillation in crime rates during the period in question, although there now exists evidence that pandemic hotspots may actually dampen crime rate changes. These findings provide insight into crime during the pandemic, but much additional research is warranted to provide a fuller picture of the phenomenon.

\section{References}

Altman, L., J. Cram, V., Gonzalez, and J. Letona. 2021. One day at a time...A comprehensive COVID19 timeline. KCET News. https://www.kcet.org/news-community/a-year-in-pandemia/one-day-at-atime-a-comprehensive-covid-19-timeline

Ashby, M. 2020. Initial evidence on the relationship between the coronavirus pandemic and crime in the United States. Crime Science 9 (6): 1-16. https://doi.org/10.1186/s40163-020-00117-6.

Association of Certified Fraud Examiners. 2020. Fraud in the wake of COVID-19: benchmarking report. https://www.acfe.com/uploadedFiles/ACFE_Website/Content/covid19/Covid-19\%20Benchmar king\%20Report\%20December\%20Edition.pdf

Augusto, D., E. Pollock, and S. Flick. 2020. The push of disasters and pull of pandemics: Law Enforcement Officers' perspectives on crime and policing during disasters and the COVID-19 pandemic. International Public Safety Association Journal 5(1):1-37. https:/www.joinipsa.org/resources/ IPSA\%20Journal/IPSA\%20Journal\%20Fifth\%20Edition\%20-\%20December\%202020.pdf

Bay Area News Group. 2020. Which California counties will have a coronavirus curfew? Here's a map. The Mercury News. https://www.mercurynews.com/2020/11/19/which-california-counties-willhave-a-coronavirus-curfew-heres-a-map/

Boman, J.H., and O. Gallupe. 2020. Has COVID-19 changed crime? Crime rates in the United States during the pandemic. American Journal of Criminal Justice 45 (4): 537-545. https://doi.org/10.1007/ s12103-020-09551-3.

Champlin, B. 2020. A timeline of COVID-19 in Los Angeles. We Like LA.com. https://www.welikela. com/timeline-covid-19-crisis-los-angeles/

Cheung, L., and P. Gunby. 2021. Crime and mobility during the COVID-19 lockdown: a preliminary empirical exploration. New Zealand Economic Papers 1-8. https://doi.org/10.1080/00779954.2020. 1870535

Chodosh, S. 2021. 5 Graphs that show how bad COVID-19 is in LA county. Popular Science. https:// www.popsci.com/story/health/los-angeles-covid/

Cohen, L.E., and M. Felson. 1979. Social change and crime rate trends: a routine activity approach. American Sociological Review 44: 588-608.

DeLiema, M., M. Deevy, A. Lusardi, and O. S. Mitchell. 2018. Exploring the risks and consequences of elder fraud victimization: evidence from the health and retirement study. Wharton Pension Research Council Working Papers (17)

Dietze, P.M., and A. Peacock. 2020. Illicit drug use and harms in Australia in the context of COVID19 and associated restrictions: anticipated consequences and initial responses. Drug and Alcohol Review 39 (4): 297-300. https://doi.org/10.1111/dar.13079.

Dunton, G.F., B. Do, and S. D. Wang. 2020. Early effects of the COVID-19 pandemic on physical activity and sedentary behavior in children living in the U.S. BMC Public Health 20(1351). https://doi.org/ $10.1186 / \mathrm{s} 12889020-09429-3$ 
Ehrlich, I. 1973. Participation in illegitimate activities: a theoretical and empirical investigation. Journal of Political Economy 81 (3): 521-565.

Everytown for Gun Safety Support Fund. 2021. Gun violence and COVID-19 in 2020 [Report]. Everytown Research \& Policy. https://everytownresearch.org/report/gun-violence-andcovid-19-in-2020-a-year-ofcolliding-crises/\#key-findings

Felson, R.B., and B. Lantz. 2016. When are victims unlikely to cooperate with the police? Aggressive Behavior 42: 97-108. https://doi.org/10.1002/ab.21626.

Friedson, A.I., D. McNichols, and J.J. Sabia. 2021. Shelter-in-place orders and public health: evidence from California during the COVID-19 pandemic. Journal of Policy Analysis and Management 40 (1): 258283. https://doi.org/10.1002/pam.22267.

Frois, C. 2020. COVID-19 pandemic and social distancing in prisons. Anthropology Today 36 (3): 25-26.

Godin, M. 2020. French government to house domestic abuse victims in hotels as cases rise during coronavirus lockdown. Time. https://time.com/5812990/francedomestic-violence-hotel-coronavirus/

Gomez, C.T. 2020. Organised crime governance in times of pandemic: the impact of COVID-19 on gangs and drug cartels in Columbia and Mexico. Journal of the Society for Latin American Studies 39 (S1): 12-15. https://doi.org/10.1111/blar.13171.

Halford, E., A. Dixon, G. Farrell, N. Malleson, and N. Tilley. 2020. Crime and coronavirus: social distancing, lockdown, and the mobility elasticity of crime. Crime Science 9 (1): 1-12. https://doi.org/10.1186/ s40163-020-00121-w.

Haskell, J. 2020. Where is the epicenter of COVID-19 in Los Angeles county? abc7 Eyewitness News. https://abc7.com/coronavirus-covid-19-most-cases-in-laepicenter-county/6343770/

Hellmann, J. 2020. NYC Saw 24,000 “excess deaths" at peak of coronavirus outbreak. The Hill. https://thehill. com/policy/healthcare/497156-nyc-saw-24000-excessdeaths-ascoronavirus-ravaged-health-care-system

Hsu, L., and A. Henke. 2020. COVID-19, staying at home, and domestic violence. Review of Economics of the Household 19: 145-155. https://doi.org/10.1007/s11150-020-09526-7.

Irick, W. 2021. California's four-tiered, color-coded coronavirus system explained. NBC News. https://www. nbclosangeles.com/news/local/guide-californiacoronavirus-tier-restrictions-system-pandemic-covid-19/ 2511920/

Klein, A., and E. Smith. 2021. Explaining the economic impact of COVID-19: core industries and the hispanic workforce. Brookings. https://digitalscholarship.unlv.edu/brookings_policybriefs_reports/2/

Layachi, O.B. 2020. International and national obligations to protect from the risks of pharmaceutical crime: the crime of counterfeit pharmaceutical products in the COVID19 crisis. Systematic Reviews in Pharmacy 11 (2): 648-657. https://doi.org/10.5530/srp.2020.2.93.

Lichtenberg, P.A., L. Stickney, and D. Paulson. 2013. Is psychological vulnerability related to the experience of fraud in older adults? Clinical Gerontologist 36 (2): 132-146. https://doi.org/10.1080/07317 115.2012.749323.

Lichtenberg, P.A., M.A. Sugarman, D. Paulson, L.J. Ficker, and A. Rahman-Filipiak. 2016. Psychological and functional vulnerability predicts fraud cases in older adults: results of a longitudinal study. Clinical Gerontologist 39 (1): 48-63. https://doi.org/10.1080/07317115.2015.1101632.

Los Angeles Police Department. 2021a. Crime Data from 2010 to 2019. https://data.lacity.org/Public-Safety/ Crime-Data-from-2010-to-2019/63jg-8b9z

Los Angeles Police Department. 2021b. Crime data from 2020 to present. https://data.lacity.org/PublicSafety/Crime-Data-from-2020-to-Present/2nrs-mtv8

Macias Jr., M. 2019. Los Angeles City council declares LA a Sanctuary City. Courthouse News Service. https://www.courthousenews.com/los-angeles-city-councildeclares-la-a-sanctuary-city/

Mahbubani, R., and D. Mosher. 2020. "In search of the apex and the other side of the mountain": the coronavirus has killed more than 4,100 new yorkers in just over a month, and the worst is still to come. Business Insider. https://www.businessinsider.com/new-york-coronavirus-crisis-1-month-cases-surge apex-2020-4

McKay, T., J. Metzl, and J. Piemonte. 2020. Effects of statewide coronavirus public health measures and state gun laws on American gun violence. Social Science Research Network. https://papers.ssrn.com/sol3/ papers.cfm?abstract_id=3680050

Miller, J.M., and A. Blumstein. 2020. Crime, justice \& the COVID-19 pandemic: toward a national research agenda. American Journal of Criminal Justice 45 (4): 515-524. https://doi.org/10.1007/ s12103-020-09555-z.

Mills, R.R. 2020. The current state of financial crime awareness and readiness during a pandemic-an analysis of definitions, prevention, detection and mitigation [Master's thesis, Utica College]. ProQuest. https://search.proquest.com/openview/2e0fe676634392a4a51e8bc03b73ec8b/1?pqorigsite=gscholar\& $\mathrm{cbl}=44156$ 
Mohler, G., A.L. Bertozzi, J. Carter, M.B. Short, D. Sledge, G.E. Tita, and P.J. Brantingham. 2020. Impact of social distancing during COVID-19 pandemic on crime in Los Angeles and Indianapolis. Journal of Criminal Justice 68: 101692. https://doi.org/10.1016/j.jcrimjus.2020.101692.

Panchal, N., R. Kamal, C. Cox, and R. Garfield. 2021. The implications of COVID-19 for mental health and substance use. Kaiser Family Foundation. https://www.kff.org/coronavirus-covid-19/issue-brief/theimplications-of-covid-19-formental-health-and-substance-use/

Payne, J.L., A. Morgan, and A.R. Piquero. 2020. COVID-19 and social distancing measures in Queensland, Australia, are associated with short-term decreases in recorded violent crime. Journal of Experimental Criminology. https://doi.org/10.1007/s11292-020-09441y.

Redondo, S., R.A. Goncalves, J. Nistal, C. Soler, J.S. Moreira, J. Andrade, and A. Andres-Pueyo. 2020. Corrections and crime in span and Portugal during the Covid-19 pandemic: impact, prevention and lessons for the future. Victims \&amp; Offenders 15 (7-8): 1156-1185. https://doi.org/10.1080/15564886.2020. 1827108.

Reuters. 2020. U.S. CDC reports record 3,764 coronavirus deaths in a day. U.S. News. https://www.usnews. com/news/us/articles/2020-12-31/us-cdc-reports-record3-764-coronavirus-deaths-in-a-day

Ritscher, C. 2021. COVID-19 and international crimes trials in Germany. Journal of International Criminal Justice. https://doi.org/10.1093/jicj/mqaa055.

Salyer, S.J., J. Maeda, S. Sembuche, Y. Kebede, A. Tshangela, M. Moussif, C. Ihekweazu, N. Mayet, E. Abate, A. Ouma, and J. Nkengasong. 2021. The first and second waves of the COVID-19 pandemic in Africa: a cross-sectional study. The Lancet 397 (10281): P1265-P1275. https://doi.org/10.1016/S01406736(21)00632-2.

Samra, S., D. Hsieh, T. Schneberk, and P. Bourgois. 2020. 2 Interpersonal and structural violence in the wake of COVID-19. American Journal of Public Health 110 (11): 1659-1661. https://doi.org/10.2105/AJPH. 2020.305930 .

Stringini, M., and K. J. Hiramoto. 2020. Is Los Angeles county the new "epicenter" of the COVID-19 pandemic? Fox 11 News. https://www.foxla.com/news/islosangeles-county-the-new-epicenter-of-the-covid19-pandemic

Tyler, T.R., J. Jackson, and A. Mentovich. 2015. The consequences of Being an object of suspicion: potential pitfalls of proactive police contact. Journal of Empirical Legal Studies 12 (4): 602-636.

United Nations Office on Drugs and Crime. 2020. Research brief: effect of the COVID-19 pandemic and related restrictions on homicide and property crime. https://www.unodc.org/documents/data-and-analy sis/covid/Property_Crime_Brief_2020.pdf

United States Internal Revenue Service. (n.d.) IRS Unveils "Dirty Dozen” List of Tax Scams for 2020; Americans urged to be vigilant to these threats during the pandemic and its aftermath. https://www. irs.gov/newsroom/irs-unveils-dirty-dozen-list-of-tax-scams-for-2020americans-urged-to-be-vigilant-tothese-threats-during-the-pandemic-and-its-aftermath

Usher, K., N. Bhullar, J. Durkin, N. Gyamfi, and D. Jackson. 2020. Family violence and COVID-19: increased vulnerability and reduced options for support. International Journal of Mental Health Nursing 29 (4): 549-552. https://doi.org/10.1111/inm.12735.

Wagers, S. 2020. Domestic violence growing in wake of coronavirus outbreak. The Conversation. https:// theconversation.com/domestic-violence-growing-in-wake-ofcoronavirus-outbreak-135598

Whiteley, P. 1980. Time series analysis. Quality and Quantity 14 (1): 225-247.

Wojcik, M.E., and D.W. Austin. 2020. Criminal justice and COVID-19. Criminal Justice 35(3). https://www. americanbar.org/groups/criminal_justice/publications/criminaljusticemagazine/2020/fall/criminal-justi ce-covid-19/

Xu, J., G. Sun, W. Cao, W. Fan, Z. Pan, Z. Yao, and H. Li. 2021. Stigma, discrimination, and hate crimes in Chinese-speaking world amid Covid-19 pandemic. Asian Journal of Crimijnology. https://doi.org/10. 1007/s11417-020-09339-8.

Zaykowski, H., E.C. Allain, and L.M. Campagna. 2019. Examining the paradox of crime reporting: are disadvantaged victims more likely to report to the police? Law \&amp; Society Review 53 (4): 1305-1340.

Publisher's Note Springer Nature remains neutral with regard to jurisdictional claims in published maps and institutional affiliations. 